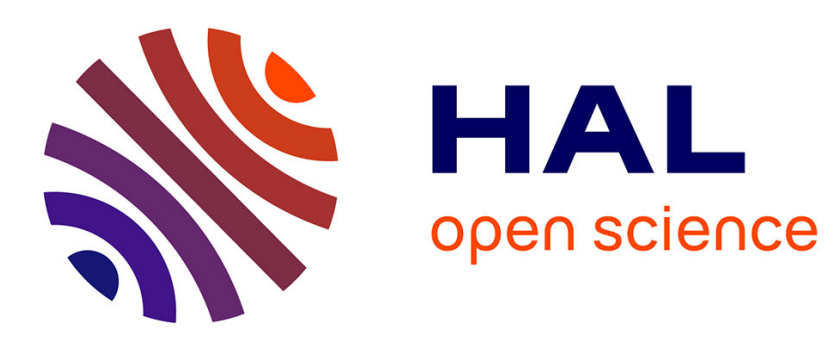

\title{
Predation pressure dynamics study of the recently introduced honeybee killer Vespa velutina: learning from the enemy
}

Karine Monceau, Nevile Maher, Olivier Bonnard, Denis Thiéry

\section{- To cite this version:}

Karine Monceau, Nevile Maher, Olivier Bonnard, Denis Thiéry. Predation pressure dynamics study of the recently introduced honeybee killer Vespa velutina: learning from the enemy. Apidologie, 2013, 44 (2), pp.209-221. 10.1007/s13592-012-0172-7 . hal-01201288

\section{HAL Id: hal-01201288 \\ https://hal.science/hal-01201288}

Submitted on 17 Sep 2015

HAL is a multi-disciplinary open access archive for the deposit and dissemination of scientific research documents, whether they are published or not. The documents may come from teaching and research institutions in France or abroad, or from public or private research centers.
L'archive ouverte pluridisciplinaire HAL, est destinée au dépôt et à la diffusion de documents scientifiques de niveau recherche, publiés ou non, émanant des établissements d'enseignement et de recherche français ou étrangers, des laboratoires publics ou privés.

$$
\text { Copyright }
$$




\title{
Predation pressure dynamics study of the recently introduced honeybee killer Vespa velutina: learning from the enemy
}

\author{
Karine Monceau, ${ }^{1,2}$ Nevile Maher, ${ }^{1,2}$ Olivier Bonnard ${ }^{1,2}$, Denis ThIÉRY ${ }^{1,2}$ \\ ${ }^{1}$ INRA, ISVV, UMR 1065 Santé et Agroécologie du Vignoble, 33883 Villenave d'Ornon, France \\ ${ }^{2}$ Université de Bordeaux, ISVV, UMR 1065 Santé et Agroécologie du Vignoble, Bordeaux Sciences Agro, 33883 \\ Villenave d'Ornon, France
}

Received 23 February 2012 - Revised 17 September 2012 - Accepted 9 October 2012

\begin{abstract}
Following the recent introduction of Vespa velutina into France, an increase in predation on domestic honeybees, Apis mellifera, has resulted from the dispersion of this hornet across the country. We aimed at providing its predation pressure dynamics at bee hives in two sites by using food traps that could be used as a comparison in future years. The number of trapped and chasing hornets in each apiary was correlated. Predation lasted 5 months on our two sites; 916 and 1,894 hornets were trapped on each site, respectively. Predation at bee hives was found to be affected by wind speed and by the seasonal effect of temperature and humidity. We also show that $V$. velutina queens and males were present during unusual periods in our traps, which may be significant to understanding their life cycle. These results are discussed with reference to the biology of other Vespine species. This study represents the first monitoring of $V$. velutina predation pressure dynamics in France. It constitutes an initial database for pest management and suggests ways of protecting bee hives.
\end{abstract}

Apis mellifera / invasive species / pest management / Vespidae / yellow-legged hornet

\section{INTRODUCTION}

Invasiveness is thought to be promoted by organismal flexibility (Lee and Gelembiuk 2008). Social hymenopterans are thus able to be successful in biological invasions because sociality favours flexibility (reviewed in Moller 1996; see also Wilson et al. 2009). Hence, many species, including Vespids, have successfully colonised a wide range of habitats worldwide (Moller 1996; Chapman and Bourke 2001; McGlynn 2002; Beggs et al. 2011), such as Polistes dominulus in North America (Cervo et al. 2000), Vespula germanica in Patagonia (Farji-

Corresponding author: D. Thiéry,

thiery@bordeaux.inra.fr

Manuscript editor: Peter Rosenkranz
Brener and Corley 1998) and Vespula vulgaris in Tasmania (Matthews et al. 2000).

The yellow-legged hornet (YLH), Vespa velutina (Lepeletier 1836), was accidentally introduced into the south-western part of France before 2004 (Villemant et al. 2006). This introduction is attributed to a single queen coming from eastern China (Villemant et al. 2006; Arca 2012). Predation on the domestic European honeybee, Apis mellifera, was rapidly reported by beekeepers around the introduction area (Villemant et al. 2006). Until now, the YLH is still spreading across the French area (Villemant et al. 2011a).

Like other social insect species, the nest is structured in a colony around one queen, and by the end of autumn, it can contain several thousands of individuals. Virgin queens and males will mate in autumn. Queens will then disperse, find shelter during winter and initiate 
new colonies the following spring whereas males will die. Honeybee predation starts in summer. Workers hunt honeybees either in flight or in front of bee hives during summer and autumn. The analysis of flesh pellets from a few nests were analysed and revealed a predominance of honeybee thoraxes in variable proportions depending on the hornet's environment: more honeybees in urban areas (ca. $65 \%$ ) than in forest and agricultural areas (ca. 33$35 \%$; Villemant et al. 2011a). Unlike the Asian honeybee, Apis cerana, which protects itself from this predator in its native area, the European honeybee has only a limited set of defences (collective warming and asphyxia of the hive intruder and stings), which are not sufficient to limit predation (Ken et al. 2005; Tan et al. 2007, 2012; Arca 2012). As a result, numerous beekeepers face serious losses within their colonies in south-western France (Monceau et al. 2012). Even though there are dramatic consequences for apiculture, those on human health are considered minor in France, as the number of hymenoptera stings reported to the French Poison Control Centres between 2004 and 2008 has not increased (de Haro et al. 2010).

In addition to other interacting antagonists which weaken honeybee colonies, such as pesticides, endo- and exo-parasites and habitat losses, fragmentation and degradation (Cox-Foster et al. 2007; Brown and Paxton 2009; Le Conte et al. 2010; Johnson et al. 2010; Potts et al. 2010; vanEngelsdorp and Meixner 2010), YLH predation has also become a worrying source of stress. Of particular concern is the risk of it extending geographically across Europe (Villemant et al. 2011b). To date, YLH nests have been observed close to the Italian border (area of Nice) and also in Spain (López et al. 2011) where predation at bee hives has begun (Goldarazena, personal communication). Individuals have also been observed in Belgium (Bruneau 2011) and Portugal. Pessimistic scenarios thus predict its extension Europe wide. Although the eradication of the YLH is no longer possible, pest management programs can be implemented and are required.

Having knowledge of basic biological characteristics - both in the invaded and native area
(Matthews and Marsh-Matthews 2011) and particularly from population dynamics (Geier 1966) — can be beneficial to pest management plans. Analysing both temporal and spatial variations, as well as identifying the climatic factors which can affect seasonal population dynamics, can be helpful for defining a management plan (Choi et al. 2011; Han et al. 2011). To date, biological data on the YLH remains scarce, because it is not a pest in its native area, except in India where its predation pressure dynamics have been studied (Abrol 1994).

Here, we propose to analyse in more detail the predation pressure dynamics of the YLH in the French invaded area. This study was carried out on hives during the predation period in the early stages of the invasion (2008) and was designed in order to identify specific key periods during which predation on honeybees can be limited. A trapping procedure was used to monitor predation pressure dynamics. Predation on two apiaries was compared, one in an urban area and the other one in a suburban area on the edge of a forest and of agricultural land. Our first goal was to assess the efficiency of the food trapping technique. To validate this method, the number of chasing YLHs in each apiary was noted and compared with that of trapped ones. Several studies on Vespidae have documented the relationship between climatic conditions (i.e., temperature, humidity, rainfall, solar insolation, etc.) and foraging activities (Ishay 2004; da Rocha and Giannotti 2007; Kasper et al. 2008; de Castro et al. 2011); the impact of abiotic parameters on YLH predation was thus considered. Finally, the variation in body mass of trapped YLHs was also analysed to understand the relationship between predation pressure and population dynamics.

\section{MATERIAL AND METHODS}

\subsection{Study area}

For our suburban site, we selected an apiary belonging to a professional beekeeper with 44 hives (Artigues-près-Bordeaux (ART), GPS-4451'37.20" 
$\mathrm{N}$ and $0^{\circ} 28^{\prime} 43.28^{\prime \prime} \mathrm{W}$ ), classified as semi-natural area in a deciduous forest surrounded by a "discontinuous urban fabric" (Corine Land Cover, respectively codes 313 and 112, Bossard et al. 2000). The traps were placed close to a separate group of 14 hives, the other hives being $50 \mathrm{~m}$ distant. The urban site was an experimental apiary on the grounds of our research institute (INRA, Villenave d'Ornon (VIL), GPS - $44^{\circ}$ $47^{\prime} 27.05^{\prime \prime} \mathrm{N}$ and $\left.0^{\circ} 34^{\prime} 38.35^{\prime \prime} \mathrm{W}\right) ; 25$ ha of "drained arable land" surrounded by a "discontinuous urban fabric" (Corine Land Cover, respectively codes 212 and 112, Bossard et al. 2000) close to the large city of Bordeaux in an urban area. The experimental plot consisted of nine bee hives aligned between rows of chestnut trees. The two experimental sites were about $11 \mathrm{~km}$ apart and were separated by the Garonne River.

\subsection{Food traps}

Food traps (Figure 1) placed close to the hives were used as an alternative attractive food source competing with the prey. All the traps were placed on ART on 11th June and on VIL on 25th June, and they were removed on 10th December on both sites. In each apiary, four traps were positioned $5 \mathrm{~m}$ from the hives and placed $1 \mathrm{~m}$ above the ground, either hung in trees (ART) or placed on supports between them (VIL). Each trap contained a bait consisting of $1 \mathrm{~L}$ of diluted apple concentrate $(20 \%$ in water), $8 \mathrm{~g}$ of proteinic wasp bait (Acto), and $100 \mu \mathrm{L}$ of Tween $80^{\circledR}$ (Sigma) as a surfactant in order to drown the hornets. The apple bait was similar to that developed for monitoring pest insects in vineyards (see Thiéry et al. 2006 for details). Baits were changed once a week (on a Monday), and captured YLHs and other species (European hornet, honeybees, wasps, Diptera, Lepidoptera, Coleoptera and Neuroptera) were noted three times a week (on a Monday, Wednesday and Friday) at 11:00. The YLHs were then frozen in groups according to collection date and site for weighing. The preying YLHs observed in front of each hive on the trapping site were counted for 1 min during each trap check (Monday, Wednesday and Fridays).

\subsection{Casts, sexes and dry weight}

Female and male YLHs were sorted according to collection date. As it is not possible to morphologically differentiate foundresses from workers, we used dry body mass in order to differentiate the different castes. Based on Monceau et al. (2012), the dry body

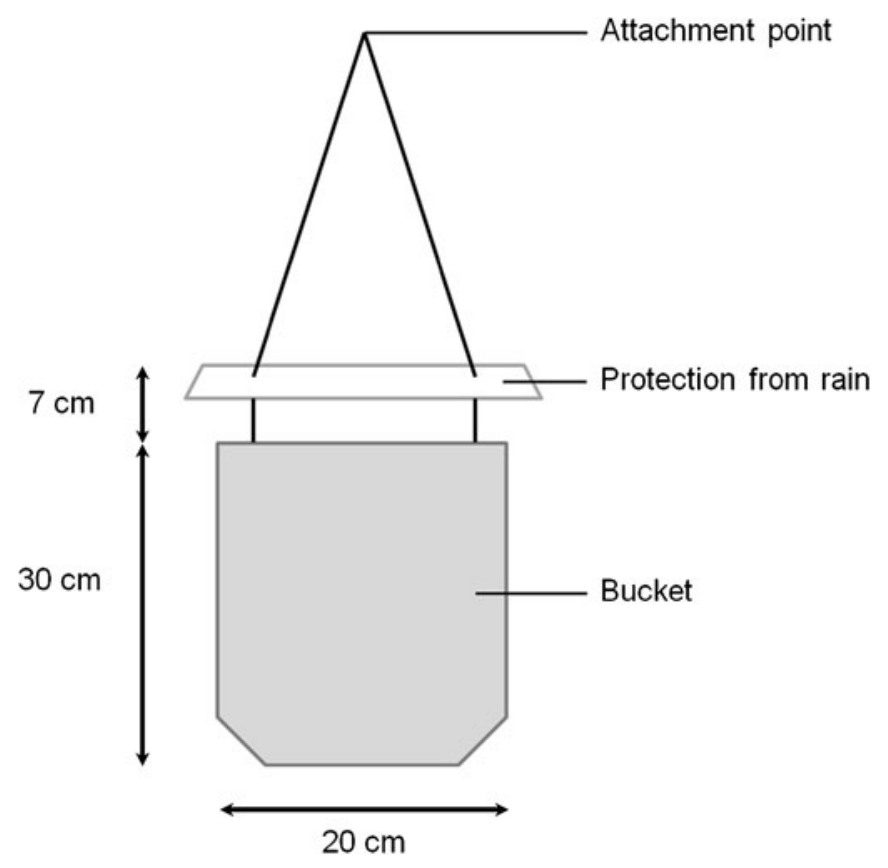

Figure 1. Food trap design used in the present study with dimensions. The bucket is cylindrical. 
mass of a foundress is on average $204 \pm 37 \mathrm{mg}$ (range, 156-387 mg). Up to 30 YLHs (range, 1-30; depending on trapping sample size) were individually weighed for each collection date for both ART and VIL sites. When present, all males were weighed (range, 1-8). Hornets were first dried at $70{ }^{\circ} \mathrm{C}$ in a stove for at least $2 \mathrm{~h}$ and then weighed to the nearest $0.1 \mathrm{mg}$ using a precision scale (Sartorius MC $210 \mathrm{~S}$ ).

\subsection{Climatic data}

Climatic data were extracted from the network of INRA weather stations using the Climatik application (v. 1.2, Agroclim INRA). The closest weather station to each site was used: that of ART on the site of Domaine du Grand Parc (INRA, Latresne, on the same bank of the Garonne River) and that of VIL located in the same area on the trapping site. Hourly temperature (in degree Celsius) and humidity (in per cent) were recorded for both sites, but anemometric data (meters per second) were only available for VIL. The average of temperature, humidity and maximal wind speeds was taken between two consecutive collection dates.

\subsection{Statistics}

Prior to carrying out the analyses, normality was checked (Shapiro-Wilk test) in order to choose the appropriate next step. The consistency of YLH trapping within the site ( $\mathrm{R}$ for repeatability) was investigated with the generalised linear mixed-effects models (GLMM) for link-scale repeatabilities adapted for counting data (Poisson model with log link, accounting for multiplicative overdispersion, Nakagawa and Schielzeth 2010). Spearman's rank correlation tests were used to assess the relationship between trapped YLHs and chasing YLHs. YLH trapping dynamics on ART were compared with those on VIL using the Peto and Peto (1972) modification of the Gehan-Wilcoxon test (Gehan 1965), belonging to the $G$-rho family of tests for survival analysis based on $\chi^{2}$-statistics. The first and last dates for this analysis were 11th June and 10th December, respectively. Overdispersed Poisson log-linear generalised linear models (GLMs) were used to compare the number of trapped YLHs on each site and for all dates. Poisson models corrected for overdispersion were preferred to classical Poisson models based on overdispersion tests. The statistical significance of each parameter was assessed with likelihood ratiobased $\chi^{2}$-statistics for unbalanced design (Fox and Weisberg 2011). This procedure was also used to test the relationship between the number of trapped YLHs and temperature, humidity and wind speed including the seasonal effect (month $\times$ temperature effect). Monthly variations of temperature, humidity and wind speed were tested with Jonckheere tests for ordered alternatives (Siegel and Castellan 1988). It is possible to apply this test to $k$ independent samples when the ordering of the groups can be specified a priori. Because the alternative hypothesis specifies the order of the medians, the test is one-tailed (Siegel and Castellan 1988). The GLM model with an identity link function was used to analyse logtransformed body mass variation within months, sexes and sites. The statistical significance of parameters was assessed by analysing the deviance based on $F$-statistics for unbalanced design. Tukey's honestly significant difference (THSD) tests were used to identify differences for more than three factors. Unilateral binomial tests were used to test if foundresses were more numerous in October and November.

All statistics were calculated using R software (v. 2.10.1 R Development Core Team 2008) implemented with the following packages: the $r p t R$ package for the repeatability analysis (Nakagawa and Schielzeth 2010); the epicalc package for overdispersion detection; the dispmod package for fitting overdispersed Poisson log-linear GLMs; the car package for deviance analysis in unbalanced design; and the survival package for the Gehan-Wilcoxon test.

\section{RESULTS}

On site, all four traps caught the same number of YLHs (GLMM, Poisson family: $\mathrm{ART}-R=0.60, P=0.001$ and VIL $-R=0.86$, $P=0.001)$. Thus, the number of trapped YLHs used thereafter was obtained by pooling the sample size over the four traps per site. YLHs represented 0 to $70 \%$ of the total insects noted depending on the month (Table I). Between June and December, 2,453 females (ART $=704$ and $\mathrm{VIL}=1,749)$ and 68 males $(\mathrm{ART}=46$ and 
Table I. Percentage of insect groups trapped during the survey per month and per site.

\begin{tabular}{lrrrrrrr}
\hline & June & July & August & September & October & November & December \\
\hline ART & & & & & & & \\
YLH & 4 & 5 & 16 & 10 & 22 & 23 & 6 \\
European hornet & 6 & 21 & 32 & 12 & 19 & 1 & 0 \\
Honeybee & 1 & 7 & 7 & 2 & 1 & 0 & 24 \\
Wasp & 0 & 2 & 1 & 2 & 2 & 1 & 0 \\
Diptera & 39 & 49 & 31 & 59 & 48 & 73 & 71 \\
Lepidoptera & 39 & 10 & 12 & 14 & 8 & 2 & 0 \\
Coleoptera & 10 & 4 & 1 & 0 & 0 & 0 & 0 \\
Neuroptera & 0 & 1 & 0 & 2 & 2 & 0 & 0 \\
VIL & & & & & & & 0 \\
YLH & 0 & 1 & 6 & 14 & 45 & 70 & 0 \\
European hornet & 1 & 2 & 2 & 2 & 1 & 0 & 0 \\
Honeybee & 3 & 1 & 0 & 0 & 0 & 0 & 0 \\
Wasp & 2 & 0 & 0 & 0 & 0 & 0 & 0 \\
Diptera & 84 & 87 & 77 & 74 & 48 & 26 & 0 \\
Lepidoptera & 6 & 8 & 13 & 8 & 5 & 4 & 0 \\
Coleoptera & 5 & 1 & 0 & 0 & 0 & 0 & 0 \\
Neuroptera & 0 & 1 & 2 & 1 & 0 & 0 & 0 \\
\hline
\end{tabular}

$\mathrm{VIL}=22$ ) were caught (Table II). For some $\mathrm{ART}=166$ and $\mathrm{VIL}=123$ ). These individuals samples, hornets were not well-conserved (in Table II) were excluded from the body mass enough to be reliably identified (total $=286$, analysis. The number of trapped YLHs was

Table II. Summary of all YLHs caught in both ART and VIL during the survey sorted by castes.

\begin{tabular}{lrrrrrrrr}
\hline Sexes & June & July & August & September & October & November & December & Total \\
\hline ART & & & & & & & & \\
$F_{\mathrm{f}}$ & 11 & 4 & 4 & 3 & 15 & 22 & 0 & 59 \\
$F_{\mathrm{w}}$ & 4 & 35 & 168 & 130 & 212 & 96 & 0 & 645 \\
$M$ & 1 & 3 & 11 & 2 & 17 & 12 & 0 & 46 \\
$n_{\mathrm{u}}$ & 0 & 5 & 33 & 100 & 1 & 26 & 1 & 166 \\
VIL & & & & & & & & \\
$F_{\mathrm{f}}$ & 0 & 0 & 1 & 6 & 26 & 26 & 0 & 59 \\
$F_{\mathrm{w}}$ & 0 & 20 & 149 & 399 & 595 & 527 & 0 & 1,700 \\
$M$ & 0 & 0 & 1 & 4 & 1 & 16 & 0 & 22 \\
$n_{\mathrm{u}}$ & 0 & 0 & 0 & 1 & 8 & 114 & 0 & 123 \\
\hline
\end{tabular}

$F_{f}$ putative number of foundresses (see Section 2.3 for details), $F_{w}$ putative number of workers (total number of females minus $F_{\mathrm{f}}$ ), $M$ number of males, $n_{u}$ number of unidentified individuals 
correlated to the number of flying individuals observed chasing their prey in front of hives on both sites (ART $-r=0.63, P<0.0001, n=42$ (Figure 2a) and VIL $-r=0.45, P<0.01, n=54$ (Figure 2b)).

YLH captures started on 16th June on ART and on 7th July on VIL and lasted until 3rd December and 24th November, respectively. In total, 916 individuals were captured on ART and 1,894 on VIL. The highest numbers of captures on both sites occurred on 12th November, corresponding to 106 individuals on ART and 217 individuals on VIL, representing 11.57 and $11.46 \%$ of each
Figure 2. Correlation between the total number of $V$. velutina noted in front of each hive in the apiary during trap monitoring and the total individuals trapped on the sites in a ART (14 hives) and b VIL (9 hives). Each point represents a collection date.
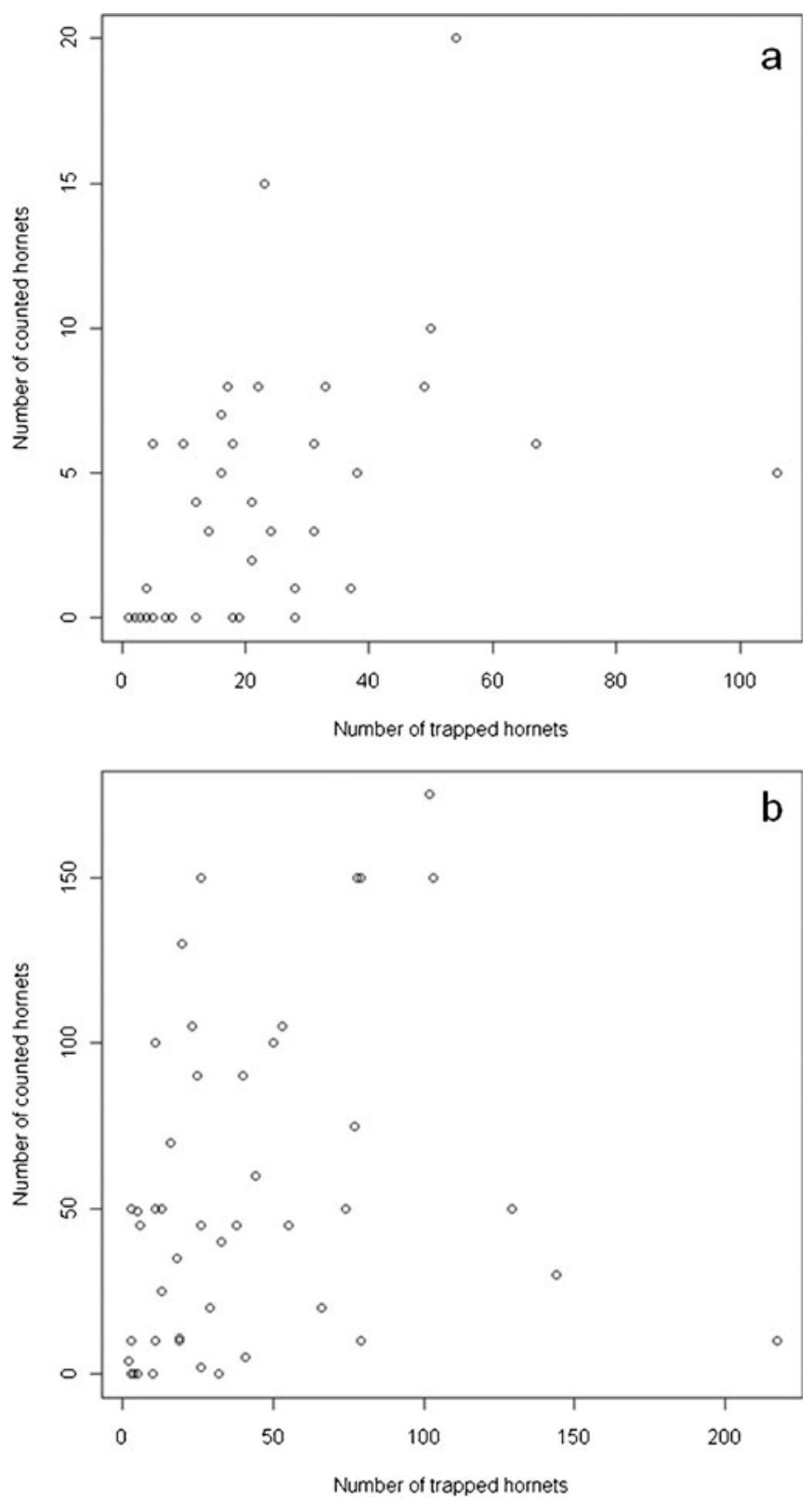
total, respectively. Overall, the number of collected YLHs varied with the date (GLM, Poisson family- $\left.\chi_{52}{ }_{52}=276.88, P<0.0001\right)$ but not the site $\left(\chi^{2}{ }_{1}=2.78, P=0.09\right)$. For both sites, the number of trapped YLHs increased for duration of approximately 3 months (GehanWilcoxon test $-\chi^{2}{ }_{1}=247, \quad P<0.0001$; Figure 3). However, this increase started 1 month earlier on ART than in VIL (28th July and 22nd August, respectively; Figure 3). The delay between the first YLH captured and the increase in predation pressure was approximately 44 days (ART - 42 days and VIL - 46 days). On ART, half of the total of trapped YLHs was reached 1 month before VIL (Figure 3).

During the survey, the number of captures differed between months (GLM, Poisson family: temperature effect analysis $-\chi^{2}{ }_{6}=283.56$, $P<0.0001$ and humidity effect analysis- $\chi_{6}^{2}=$ 287.78, $P<0.0001)$. Although the temperature and the humidity effect did not solely affect the number of captures (temperature- $\chi^{2}{ }_{1}=0.83$, $P=0.36$ and humidity $-\chi^{2}{ }_{1}=0.87, P=0.35$ ), they were significant when interacting with the month effect, suggesting a seasonal effect (temperature- $\chi_{6}^{2}=36.91, P<0.0001$ and hu- midity $\left.-\chi_{6}^{2}=13.11, P=0.04\right)$. The number of trapped YLHs increased with decreasing temperature (Figure 4a) and increasing humidity (Figure 4b), because temperature decreased during the course of the season on both sites (unilateral Jonckheere test for decreasing temperature hypothesis: ART-JT $=2,283, P<$ 0.0001 and VIL-JT=2,159.5, $P<0.0001$ ), whereas humidity increased during the course of the season (unilateral Jonckheere test for increasing humidity hypothesis: ART - JT= $13,375, P<0.0001$ and VIL-JT=13,926.5, $P<0.0001)$. On VIL, the number of YLHs in traps decreased with increasing wind speed (range, $2-5.77 \mathrm{~m} / \mathrm{s}$; that is approximately 7.20 $20.80 \mathrm{~km} / \mathrm{h}$ ), measured during the days preceding the trap survey (GLM, Poisson family- $\chi^{2}{ }_{1}=$ 4.18, $P=0.04$; Figure 4c) and also differed depending on the months $\left(\chi^{2}{ }_{6}=140.94, P<\right.$ $0.0001)$. Nevertheless, there was no wind seasonal effect on trapping (wind speed $\times$ month $-\chi_{6}{ }_{6}=3.88, P=0.69$ ), even if the wind speed decreased during the course of the season (unilateral Jonckheere test for decreasing wind speed hypothesis: ART $-\mathrm{JT}=587.5$, $P=0.01$ ).

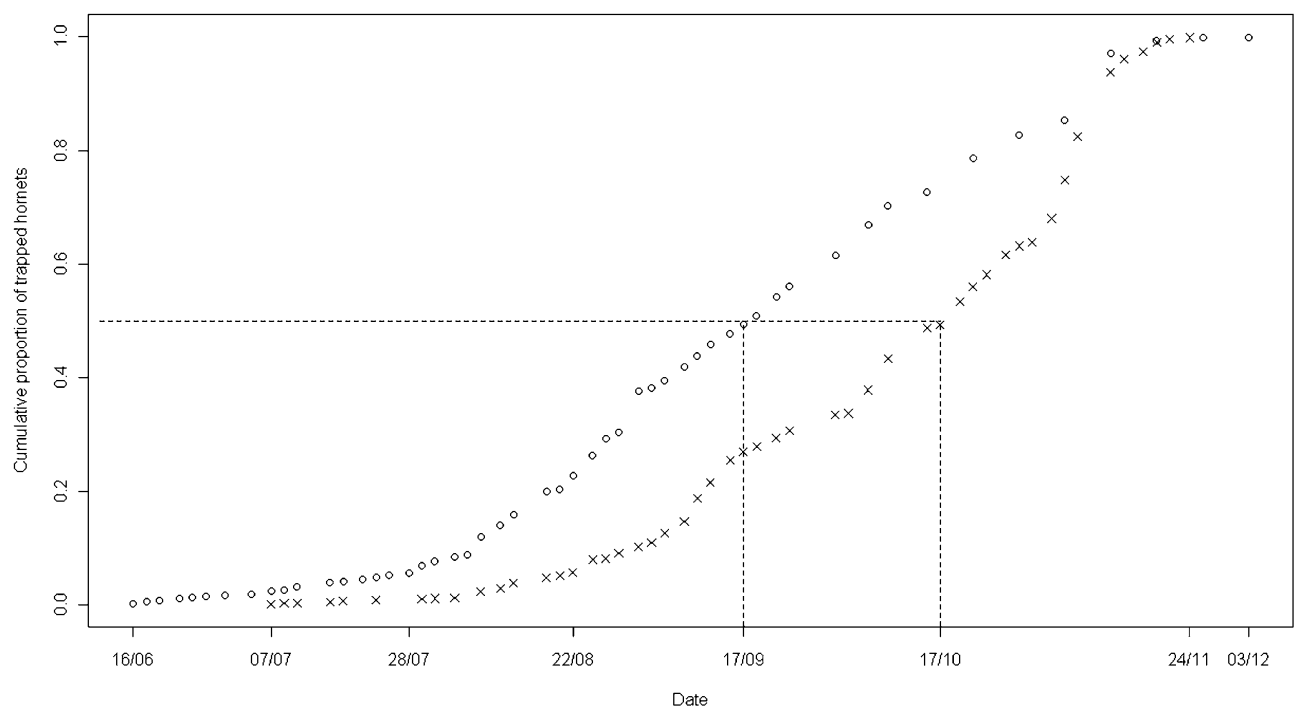

Figure 3. Cumulative proportions of total $V$. velutina trapped per collection date during the course of the survey for ART (open circles) and VIL (crosses). 
Figure 4. Variation of the total $V$. velutina trapped according to a mean temperature (pooled data for ART and VIL), b mean humidity (pooled data for ART and VIL), and c mean wind speed (VIL only) calculated between two consecutive collection dates during the survey. Predicted values fitted with the GLM model (solid line) with $95 \%$ confidence interval (dashed lines).

Throughout the entire predation period, body mass differed on each site $\left(\mathrm{GLM}-F_{1,1,625}=\right.$ 21.78, $P<0.0001)$, YLHs from ART being bigger than YLHs from VIL (respectively mean $\pm \mathrm{SD}-133.87 \pm 43.66 \mathrm{mg}, n=626$ and $131.79 \pm 23.15 \mathrm{mg}, n=1,020)$. Body mass also varied over the months $\left(\mathrm{GLM}-F_{5,1,625}=93.67\right.$, $P<0.0001)$ with an increase throughout the season from July to November; hornets caught in June were bigger than those caught in November (all THSD test $P<0.01$; Figure 5). Variation patterns differed between ART and VIL $\left(\mathrm{GLM}-F_{4}, 1,625=39.24, P<0.0001\right)$. On ART, YLHs caught in July, August and September were of equivalent body mass (THSD test $P>0.05$ ), like those caught in June and November (THSD test $P=0.24$ ), all other comparisons being different (THSD test $P<$ 0.0001). On VIL, YLHs caught in August and September were of equivalent body mass (THSD test $P=0.14$ ), as were those caught in October and November (THSD test $P=1.00$ ), and all other comparisons were different (THSD test $P<0.0001)$. Overall, monthly comparisons of ART and VIL followed the general trend of body mass increase and site differences, except in August, September and October (no difference, THSD test $P>0.77$ ). VIL individuals caught in August did not differ from ART hornets caught in July and September (THSD test $P>0.38$ ), as VIL individuals caught in November and ART individuals caught in October (THSD test $P=1.00$ ). Although, males and females were of equivalent body mass (GLM- $F_{1,}, 1,625=1.11, P=0.29$; respectively mean $\pm \mathrm{SD}-148.21 \pm 54.06 \mathrm{mg}, n=77$ and $131.81 \pm 30.90 \mathrm{mg})$, differences according to the sex of the hornets occurred by months $\left(F_{5}\right.$, $1,625=8.11, P<0.0001)$ : in June, females were heavier than males (THSD $P<0.0001$ ), and
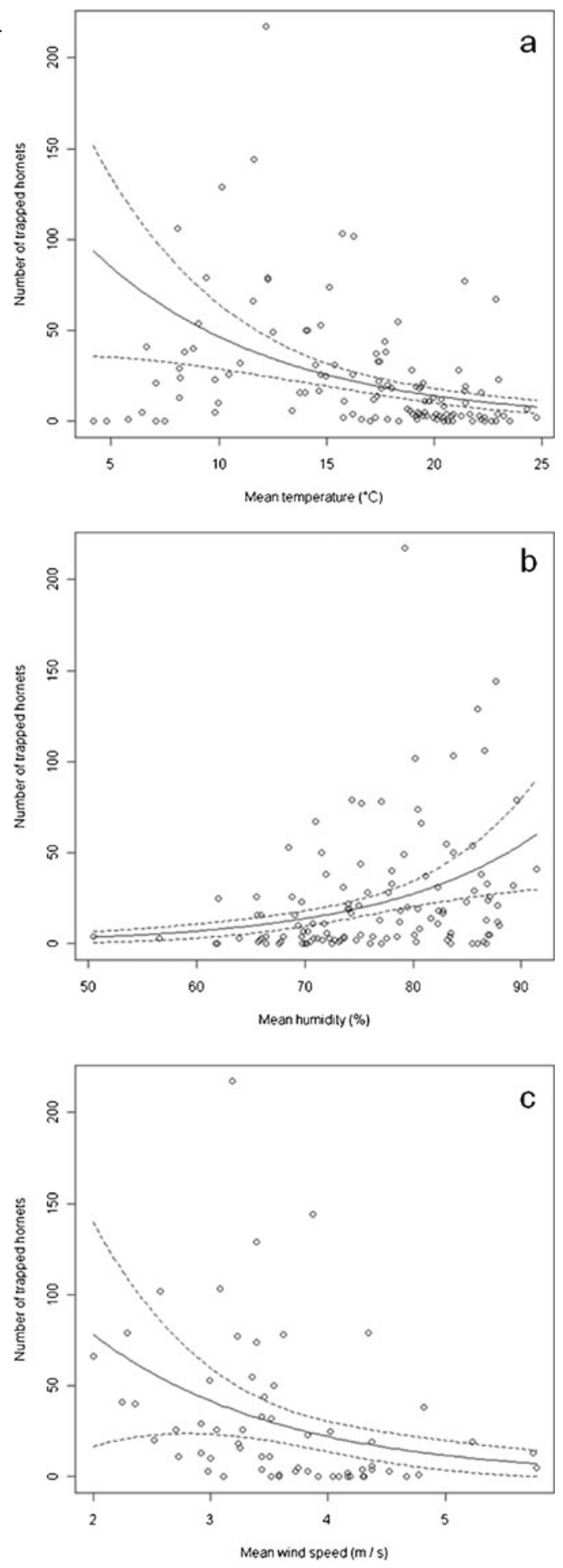


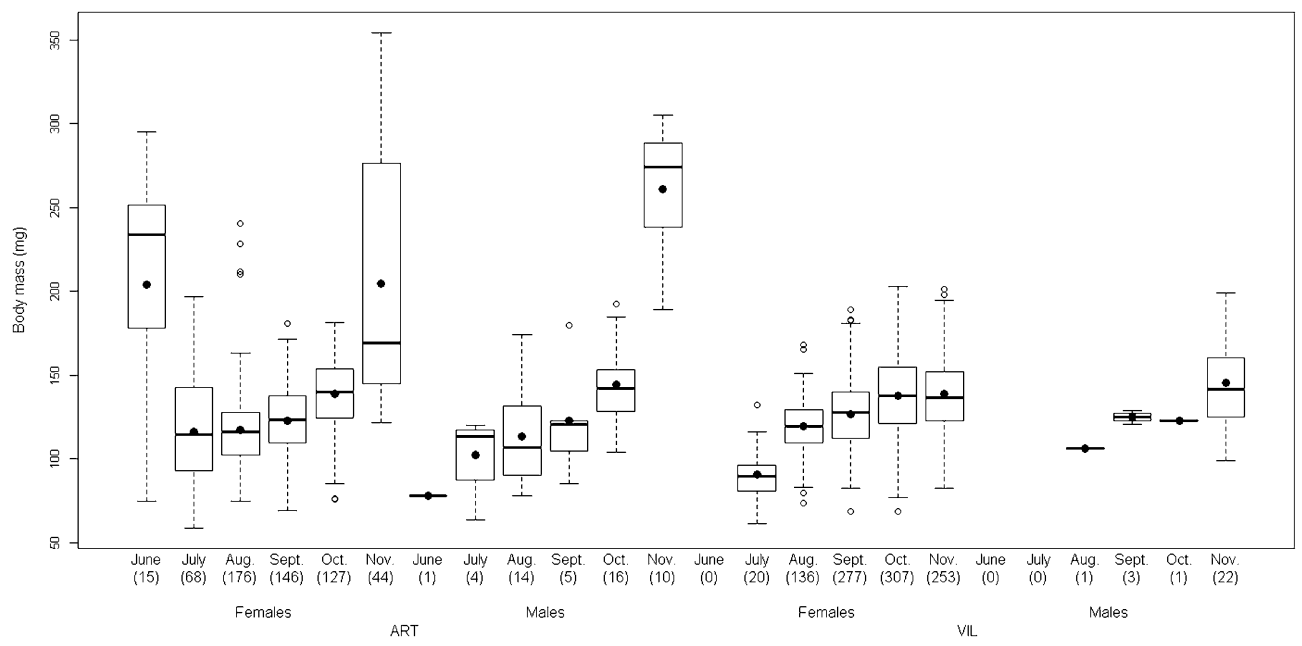

Figure 5. Body mass variation of $V$. velutina by months, sexes and castes. Boxes, solid line, black point, dashed lines, and open circles represent $50 \%$ of all values, medians, means, 1.5 interquartile range, and extreme values, respectively. Numbers are sample sizes per month.

males were bigger than females in November $(P<0.0001)$. There was no difference in body mass between males and females during the remaining months (all $P>0.99$ ). The female body mass increase pattern followed the general pattern described previously (THSD all $P<0.001)$, whereas male individuals were the heaviest in November (all $P<0.05$ ) and those caught in October were heavier than those caught in both July and August (THSD test $<$ $0.05)$, without differences in the remaining months (THSD test $P>0.05$ ). Differences in body mass according to the hornet's sex also occurred between sites $\left(F_{1,1,625}=7.62, P<\right.$ 0.01): males on ART were bigger than both ART females and VIL females (THSD tests, respectively $P<0.01$ and $P=0.04$ ). There was no interaction between the hornet sex, the sites and the season $\left(F_{3,1,625}=1.01, P=0.39\right)$.

From the estimated number of foundresses based on the average dry body mass data provided by Monceau et al. (2012), it was shown that this caste dominated among the hornets caught in June (Table II). Most of the foundresses in our survey appeared in October and November (unilateral binomial test: ART$P=0.03$, VIL $-P<0.0001$ and both sites$P<0.0001)$.

\section{DISCUSSION}

\subsection{Predation pressure and population dynamics}

We found a significant relationship between trapped and flying YLHs, indicating that a fair estimation of predation pressure dynamics in the two surveyed apiaries could be made from our trapping procedure. It is therefore possible to discuss the results in terms of predation pressure.

In the two different environments, predation lasted for more than 5 months. Overall, YLH predation pressure dynamics could be roughly separated into three phases. In the first phase, a very few YLHs were trapped from the beginning of the season till mid June/early July. This is followed by a large increase in predation on honeybee colonies from early August to early November, when predation decreased drastically until December. The shift between the first and the second phase indicates a shift in population dynamics. Such a pattern, called the "queen colony phase", is common in wasps (see examples provided in Spradbery 1973; Matsuura 1991; Archer 2010). The first phase of YLH predation pressure dynamics corresponds to the emergence of the first cohort of 
workers. Once they have emerged, the queen can lay new egg cohorts. Therefore, the delay between the first YLH captured and predation pressure increase would correspond to the larval stage, which has been evaluated as 48.1 days for the YLH (Archer 2010), varying with food quality and climate. Despite such variation the "first 40 days" (Spradbery 1973) appears to be consistent with our findings. It may thus be used to predict the timing of the highest predation risk. During the period of predation at bee hives, most of the trapped YLHs comprised mostly workers with a few males and queens in June. It was possible to confirm population dynamics via body mass variation. The YLHs captured in June were the heaviest (except November) and the most variable, due to a mix of queens of higher body mass and a first cohort of lighter workers. This point is important, because it indicates that queens appeared in traps during this period and then progressively disappeared. This may correspond to the end of the queen colony phase (Spradbery 1973). Another interpretation involves a bet hedging strategy (Gourbière and Menu 2009): late emergence from winter dormancy is an optimal strategy for prolonging the predation period and for adapting efficiently to new environments. In other Vespines (Spradbery 1973), queen flights have been observed until mid-June/beginning of July and one could assume a similar pattern for $V$. velutina. Such a point may be of importance, thus we believe it should receive attention in future research.

Worker body mass increased throughout the season; this could be the result of an increase in food quality and in the amount of food given to larvae. This cohort of bigger workers found later in the traps were probably fed with hunted bees, similar to Philanthus triangulum (Hymenoptera: Sphecidae), another honeybee predator. Larval size, which is related to fat reserve, is influenced by maternal provisioning and is related to the number of honeybee hunted (Strohm 2000). In several Vespidae species, the larva/worker ratio is still high after the emergence of the first workers and decreases progressively until the foundresses rear their brood (Matsuura and Yamane 1990).
Thus, during this period, larvae receive less food and/or food of lesser quality, resulting in smaller individuals. Once this worker cohort emerges in sufficient numbers, the larva/workers ratio decreases, resulting in an increase in the quality and/or quantity of the food provided and a corresponding increase in the production of workers with a higher body mass. At the end of the season, in November, heavier adults were trapped again, corresponding to the new generation of foundresses and males.

The total number of trapped YLHs during the course of the season differed on the two sites. Half the amount of YLHs was noted on ART than on VIL (916 and 1,894, respectively). Capture dynamics started 3 weeks earlier on ART than on VIL and finished 9 days later. Half of the captures were reached 30 days earlier on ART than on VIL. Predation pressure on VIL increased more slowly than on ART during the half of the capture period and more quickly during the second half. These differences can be attributed to the more numerous hives in the ART apiary than in that of VIL (14 vs. 9), as well as to a potentially richer ecosystem of arthropod prey on ART (woodland landscapes), which has the effect of diluting predation pressure. The overall density of YLH on each site could not be estimated for two reasons: (1) the national YLH nest database (INPN 2010) reports only numbers of nests and not size and (2) the local contribution of each nest to predation is so far unknown. Although food patch density (i.e., apiaries) could also have an effect on predation pressure within apiaries, we believe that providing data on the foraging range of the YLH around its nests is a priority.

Temperature, humidity and wind speed are known to affect the activities of several Vespidae (da Rocha and Giannotti 2007; Kasper et al. 2008; de Castro et al. 2011), and Apidae (Lundberg 1980; Burrill and Dietz 1981; Omoloye and Akinsola 2006; Neves et al. 2011). Within this survey, the only factor which appears to modulate predation pressure is wind speed, probably because it is a limiting factor for flying and most particularly because the stationary flight required for catching honeybees may 
be more costly on windy days. Wind is also a key factor for individuals that have to return to their high altitude nest. We found that temperature and humidity did not have an effect per se, but did have some influence when linked to seasonal variation. Although predator activity can be driven by its own biological clock (Giller and Sangpradub 1993), it can also be related to the activity of the prey (Kotler et al. 2002). Thus, the observed seasonal effect on the hunting behaviour of the YLH could result from another effect: the YLH matching its activity to the honeybee foraging activity, which depends on climate. Thus, we believe that these relationships should be studied daily in order to identify the "optimal climatic windows" corresponding to increased or reduced predation risk.

\subsection{Management perspectives}

Using the method of food trapping in order to capture chasing YLHs appears to be a reliable tool for monitoring predation pressure on honeybees, and it could be used both for monitoring the onset of predation and its intensity. In our study, the 40day delay between the first capture and the appearance of the first YLH hunters in apiaries is consistent in both environments. The first predator captures could thus be a means of providing beekeepers with a warning signal. In our opinion, the 40-day period is the most vulnerable stage for the YLH colonies after nest initiation by foundresses. Indeed, if YLH hunters are trapped during this period, larvae will receive food reduced in quantity and quality, and as a consequence their growth will be altered. Once the predation pressure increases, food trapping is not sufficient to limit YLH population growth, but it could still be used to protect apiaries.

Obviously, in order to protect honeybees from YLH predation, season-round trapping seems essential, but unfortunately it is not sufficient enough to effectively protect bee hives. It is important to highlight here that food trapping generates serious side-effects on entomofauna and it should therefore be used carefully as an apiary protection tool. Nevertheless, pending a more selective solution, we recommend that beekeepers multiply traps when the first YLHs are detected. New foundresses can also be caught if the traps are maintained throughout December. Foundress trapping in spring is quite controversial due to its impact on entomofauna (Haxaire and Villemant 2010; Monceau et al. 2012). Although trapping pests in agriculture involves a trade-off between its beneficial effect as a pest control and its side effect on biodiversity, such a trade-off would be more advantageous for biodiversity at the end of autumn/early winter than in spring.

\section{ACKNOWLEDGEMENTS}

This research project was funded by France Agrimer \# 797/2007-2010. This work benefited from the technical contribution of E. Segura. We are grateful to Mr. J. Martrenchar for allowing us to work in his apiary. We also thank Dr. J. Moreau for his helpful comments on our manuscript and Dr. S. Hayes for proofreading our English.

Dynamique de la pression de prédation de Vespa velutina, prédateur d'abeilles récemment introduit: apprendre de l'ennemi.

Apis mellifera / espèce invasive / gestion des ravageurs / Vespidae / frelon asiatique à pattes jaunes / France

Eine Studie zur Dynamik des Prädationsdrucks durch den kürzlich eingeführten Honigbienenjäger Vespa velutina: Vom Feind lernen.

Apis mellifera / invasive Arten / Schädlings-Management / Vespidae/Hornisse

\section{REFERENCES}

Abrol, D.P. (1994) Ecology, behaviour and management of social wasp, Vespa velutina Smith (Hymenoptera: Vespidae), attacking honeybee colonies. Korean J. Apic. 9, 5-10

Arca, M. (2012) Caractérisation génétique et étude comportementale d'une espèce envahissante en France: Vespa velutina Lepeletier (Hymenoptera, Vespidae). Ph.D. dissertation, Université Pierre et Marie Curie, Paris

Archer, M.E. (2010) The queen colony phase of vespine wasps (Hymenoptera, Vespidae). Insectes Soc. 57, 133-145 
Beggs, J.R., Brockerhoff, E.G., Corley, J.C., Kenis, K., Masciocchi, M., Muller, F., Rome, Q., Villemant, C. (2011) Ecological effects and management of invasive Vespidae. BioControl 56, 505-526

Bossard, M., Feranec, J., Otahel, J. (2000) CORINE land cover technical guide-Addendum 2000. European Environment Agency-Technical report n 40. 105 p

Brown, M.J.F., Paxton, R.J. (2009) The conservation of bees: a global perspective. Apidologie 40, 410-416

Bruneau, E. (2011) Le frelon asiatique, déjà là! ActuApi 55, $1-6$

Burrill, R.M., Dietz, A. (1981) The response of honey bees to variations in solar radiations and temperature. Apidologie 12, 319-328

Cervo, R., Zacchi, F., Turillazzi, S. (2000) Polistes dominulus (Hymenoptera, Vespidae) invading North America: some hypotheses for its rapid spread. Insectes Soc. 47, 155-157

Chapman, R.E., Bourke, A.F.G. (2001) The influence of sociality on the conservation biology of social insects. Ecol. Lett. 4, 650-662

Choi, W.I., Ryoo, M.I., Chung, Y.-J., Park, Y.-S. (2011) Geographical variation in the population dynamics of Thecodiplosis japonensis: causes and effects on spatial synchrony. Pop. Ecol. 53, 429-439

Cox-Foster, D.L., Conlan, S., Holmes, E.C., Palacios, G., Evans, J.D., Moran, N.A., Quan, P.L., Briese, T., Hornig, M., Geiser, D.M., Martinson, V., vanEngelsdorp, D., Kalkstein, A.L., Drysdale, A., Hui, J., Zhai, J., Cui, L., Hutchison, S.K., Simons, J.F., Egholm, M., Pettis, J.S., Lipkin, W.I. (2007) A metagenomic survey of microbes in honey bee colony collapse disorder. Science 318, 283-287

da Rocha, A.A., Giannotti, E. (2007) Foraging activity of Protopolybia exigua (Hymenoptera, Vespidae) in different phases of the colony cycle, at an area in the region of the Médio São Francisco River, Bahia, Brazil. Sociobiology 50, 813-831

de Castro, M.M., Guimaraes, D.L., Prezoto, F. (2011) Influence of environmental factors on the foraging activity of Mischocyttarus cassununga (Hymenoptera, Vespidae). Sociobiology 58, 138-141

de Haro, L., Labadie, M., Chanseau, P., Cabot, C., BlancBrisset, I., Penouil, F. (2010) Medical consequences of the Asian black hornet (Vespa velutina) invasion in south-western France. Toxicon 55, 650-652

Farji-Brener, A.G., Corley, J.C. (1998) Successful invasions of hymenopteran insects into NW Patagonia. Ecol. Austral. 8, 237-249

Fox, J., Weisberg, S. (2011) An R Companion to Applied Regression, 2nd edn. Sage Publications, Thousand Oaks

Gehan, E. (1965) A generalized Wilcoxon test for comparing arbitrarily singly censored samples. Biometrika 52, 203-223

Geier, P.W. (1966) Management of insect pest. Annu. Rev. Entomol. 11, 471-490
Giller, P.S., Sangpradub, N. (1993) Predatory foraging behaviour and activity patterns of larvae of two species of limnephilid cased caddis. Oikos 67, 351-357

Gourbière, S., Menu, F. (2009) Adaptive dynamics of dormancy duration variability: evolutionary tradeoff and priority effect lead to suboptimal adaptation. Evolution 63, 1879-1892

Han, P., Wang, X., Niu, C.Y., Dong, Y.C., Zhu, J.-Q., Desneux, N. (2011) Population dynamics, phenology, and overwintering of Bactrocera dorsalis (Diptera: Tephritidae) in Hubei Province. China. J. Pest. Sci. 84, 289-295

Haxaire, J., Villemant, C. (2010) Impact sur l'entomofaune des «pièges à frelon asiatique». Insectes $\mathbf{1 5 9}$, $1-6$

INPN (2010) Vespa velutina. Inventaire National du Patrimoine Naturel. <http://inpn.mnhn.fr/>. Accessed 19 January 2012

Ishay, J.S. (2004) Hornet flight is generated by sunlight energy: U.V. irradiation counteracts anesthetic effects. J. Electron. Microsc. 53, 623-633

Johnson, R.M., Ellis, M.D., Mullin, C.A., Frazier, M. (2010) Pesticides and honey bee toxicity-USA. Apidologie 41, 312-331

Kasper, M.L., Reeson, A.F., Mackay, D.A., Austin, A.D. (2008) Environmental factors influencing daily foraging activity of Vespula germanica (Hymenoptera, Vespidae) in Mediterranean Australia. Insectes Soc. 55, 288-295

Ken, T., Hepburn, H.R., Radloff, S.E., Yusheng, Y., Yiqiu, L., Danyin, Z., Neumann, P. (2005) Heatballing wasps by honeybees. Naturwissenschaften 92, 492-495

Kotler, B.P., Brown, J.S., Dall, S.R.X., Gresser, S., Ganey, D., Bouskila, A. (2002) Foraging games between gerbils and their predators: temporal dynamics of resource depletion and apprehension in gerbils. Evol. Ecol. Res. 4, 495-518

Le Conte, Y., Ellis, M., Ritter, W. (2010) Varroa mites and honey bee health: can Varroa explain part of the colony losses? Apidologie 41, 353-363

Lee, C.E., Gelembiuk, G.W. (2008) Evolutionary origins of invasive populations. Evol. Appl. 1, 427-448

López, S., Gonzáles, M., Goldarazena, A. (2011) Vespa velutina Lepeletier, 1836 (Hymenoptera: Vespidae): first records in Iberian Peninsula. Bull. OEPP/EPPO Bull. 41, 439-441

Lundberg, H. (1980) Effects of weather on foragingflights of bumblebees (Hymenoptera, Apidae) in a subalpine/alpine area. Holarct. Ecol. 3, 104-110

Matsuura, M. (1991) Vespa and Provespa. In: Ross, K.G., Matthews, R.W. (eds), The Social Biology of Wasps, Cornell University Press, pp. 232-262

Matsuura, M., Yamane, S. (1990) Biology of Vespine wasps. Springer, Berlin

Matthews, W.J., Marsh-Matthews, E. (2011) An invasive fish species within its native range: community effects 
and population dynamics of Gambusia affinis in the central United States. Freshw. Biol. 56, 2609-2619

Matthews, R.W., Goodisman, M.A.D., Austin, A.D., Bashford, R. (2000) The introduced English wasp Vespula vulgaris (L.) (Hymenoptera: Vespidae) newly recorded invading native forests in Tasmania. Aust. J. Entomol. 39, 177-179

McGlynn, T.P. (2002) The worldwide transfer of ants: geographical distribution and ecological invasions. J. Biogeogr. 26, 535-548

Moller, H. (1996) Lessons for invasion theory from social insects. Biol. Conserv. 78, 125-142

Monceau, K., Bonnard, O., Thiéry, D. (2012) Chasing the queens of the alien predator of honeybee: a water drop in the invasiveness ocean. Open J. Ecol. (in press)

Nakagawa, S., Schielzeth, H. (2010) Repeatability for Gaussian and non-Gaussian data: a practical guide for biologists. Biol. Rev. 85, 935-956

Neves, E.F., Faita, M.R., Gaia, L.D., Alves, V.V., Antonialli Jr., W.F. (2011) Influence of climate factors on flight activity of drones of Apis mellifera (Hymenoptera: Apidae). Sociobiology 57, 107-113

Omoloye, A.A., Akinsola, P.A. (2006) Foraging sources and effects of selected plant characters and weather variables on the visitation intensity of honeybee, Apis mellifera adansonii (Hymenoptera: Apidae) in the southwest Nigeria. J. Apic. Sci. 50, 39-48

Peto, R., Peto, J. (1972) Asymptotically efficient rank invariant test procedures (with discussion). J. R. Stat. Soc. Ser. A-Stat. Soc. 135, 185-206

Potts, S.G., Biesmeijer, J.C., Kremen, C., Neumann, P., Schweiger, O., Kunin, W.E. (2010) Global pollinator declines: trends, impacts and drivers. Trends Ecol. Evol. 25, 345-353

R Development Core Team (2008) R: A language and environment for statistical computing. R Foundation for Statistical Computing, Vienna, Austria. ISBN 3900051-07-0, <http://www.R-project.org>. Accessed 19 January 2012

Siegel, S., Castellan, N.J. (1988) Nonparametric statistics for the behavioral sciences, 2nd edn. McGrawHill, New York

Spradbery, J.P. (1973) Wasps: an account of the biology and natural history of social and solitary wasps. University of Washington Press, Seattle
Strohm, E. (2000) Factors affecting body size and fat content in a digger wasp. Oecologia 123, 184191

Tan, K., Radloff, S.E., Li, J.J., Hepburn, H.R., Yang, M.X., Zhang, L.J., Neumann, P. (2007) Beehawking by the wasp, Vespa velutina, on the honeybees Apis cerana and A. mellifera. Naturwissenschaften 94, 469-472

Tan, K., Wang, Z., Li, H., Yang, S., Hu, Z., Kastberger, G., Oldroyd, B.P. (2012) An 'I see you' preypredator signal between the Asian honeybee, Apis cerana, and the hornet, Vespa velutina. Anim. Behav. 83, 879-882

Thiéry, D., Rétaud, P., Cavard, X., Xuéreb, A., Dumas-Lattaque, L., Bourriau, F. (2006) Trapping Lobesia botrana females with apple juice: a valuable tool to predict oviposition? IOBC Integrated control in Viticulture. IOBC/ WPRS Bull. 29, 235-240

vanEngelsdorp, D., Meixner, M.D. (2010) A historical review of managed honey bee populations in Europe and the United States and the factors that may affect them. J. Invertebr. Pathol. 103, S80S95

Villemant, C., Haxaire, J., Streito, J.C. (2006) Premier bilan de l'invasion de Vespa velutina Lepeletier en France (Hymenoptera, Vespidae). Bull. Soc. Entomol. Fr. 111, 535-538

Villemant, C., Barbet-Massin, M., Perrard, A., Muller, F., Gargominy, O., Jiguet, F., Rome, Q. (2011a) Predicting the invasion risk by the alien bee-hawking yellow-legged hornet Vespa velutina nigrithorax across Europe and other continents with niche models. Biol. Conserv. 144, 2150-2142

Villemant, C., Muller, F., Haubois, S., Perrard, A., Darrouzet, E., Rome, Q. (2011b) Bilan des travaux (MNHN et IRBI) sur l'invasion en France de Vespa velutina, le frelon asiatique prédateur d'abeilles. In: J.-M. Barbançon and M. L'Hostis (eds.) Proceedings of the Journée Scientifique Apicole-11 February 2011, Arles. ONIRIS-FNOSAD, Nantes. pp. 3-12

Wilson, E.E., Mullen, L.M., Holway, D.A. (2009) Life history plasticity magnifies the ecological effects of a social wasp invasion. Proc. Natl. Acad. Sci. USA 106, 12809-12813 